\title{
Behind the scenes: reflecting on cross-gender interview dynamics in Mexico City
}

By Mariana Rios Sandoval (University of Amsterdam and GIRE, Group of Information for Reproductive Choice)

During the summer of 2007 I set out on a qualitative exploratory study in Mexico City that later became a masters dissertation. The study was focused on conversations with a group of men about everyday practices, expectations, ideas and feelings related to parenting, and this was an entry point into exploring constructions of fatherhood and masculinity. As I stumbled through my first in-depth interviews I felt excited, thrilled and touched, but also uneasy, overwhelmed and undeniably puzzled by a whole range of dilemmas that appeared to emerge every time I so much as stopped to think about the course of my research. The six weeks of fieldwork were a truly formative experience. An experience that made me reflect for long hours about the ethics and politics of the research process. I came to recognise that ultimately, the picture of fatherhood drawn in my study was to a certain extent negotiated with the participants, shaped by our interaction and informed by personal backgrounds, expectations, emotions and lived experiences. I believe that reflecting on this aspect of the ethnographic encounter along with communicating those reflections constitute a fundamental part of the learning exercise. The latter is precisely the purpose of the present article: communicating such reflections.

\section{The project}

Much of the research about fatherhood in Mexico, as De Keijzer (2000) points out, focuses on the various versions of a recurring theme: fathers' absence. Yet current research on fathering ideas and practices in Latin America indicates that notwithstanding the extent to which men participate in childcare and parenting, most partly define their own and others' masculinity in relation to fathering activities, and consider fatherhood a fundamental part of their lives (Escobar-Latapí 2003, FachelLeal 2000, Fuller 2001, Gutmann 1997, Olavarría 2003, Viveros 2002). The relationship between masculinity and fatherhood, and between discourse and practice, can translate into a myriad of parenting arrangements, however, very little is known about the experience of men who are actively involved in taking care of their children, the way they do it, and how they feel about the kind of parenting arrangements in which they are engaged (Gutmann 1997, 2006). My project aimed to get a glimpse of some of these "engaged fathering" experiences. 


\section{Fieldwork in a nutshell}

Once in Mexico City, I started my research with the firm intention of interviewing six to eight first-time parents of children between three months and one year of age. The reasoning behind this was that, in Mexico, only women are officially entitled to maternity leave, which allows them to take a total of 90 days off work. Officially, this time should be taken after the baby is born, although sometimes women can negotiate so that it can be taken before and after delivery depending on their needs. After this maternity leave, parents have to make other arrangements to ensure their baby is taken care of. My assumption was that up until the child's first year, couples face new necessities and challenges that unavoidably make them take steps toward establishing a particular kind of parenting arrangement.

For this project I wanted to know about the experiences of men who were actively engaged in the day-to-day childrearing activities; the men who also happen to be the most underrepresented in the literature. For this reason finding volunteers for the study was not as straightforward as I had first envisioned. After several emails, phone calls, and visits to a health care centre, it became clear that I needed to be more flexible about the characteristics of the study sample. It is not at all difficult to find first-time fathers, but finding fathers who are actively engaged in parenting activities and are also willing to talk about it, is definitely a different story. When I first told people I needed to contact papás (fathers), I would always be given names of women. This was partly due to confusion arising from the fact that papá can be used to refer both to "father" and "parent". Another reason for this confusion most likely relates to something that came up several times during the interviews, namely that parenting is usually associated with women and not men.

In order to find "involved fathers" I then used a different strategy which I call "spreading the news". I explained my research to everyone I knew, and asked them if they happened to know any men potentially suitable for the project. Whenever I saw an opportunity I also invited people to participate. The criteria for including men in the sample consequently changed. Finding first-time parents of children less than one year old proved to be complicated, so the invitation was readdressed to fathers of small children - one or more and preferably not older than five years old - who were heavily involved in parenting activities, and were willing to talk about it. "Heavily involved" remained a loose category, allowing people to interpret it freely, which eventually led to a sample of men who experienced "being a father" in very different and interesting ways. The sample in this study is therefore one of necessity, in the sense that the participants were men who were curious about the project rather than the men whom I had initially been seeking.

In this regard it became the case that all participants first knew about the project through common friends or acquaintances, or directly through me, meaning that they had some idea of what the project would be like. I began all of these ethnographic relationships through the exchange of emails and phone calls. In our first communications, I would give them more details about the study, answer their questions, invite them to participate, and ask them to set the time and place. Nine men composed the study sample, out of which six were living with the mother of their children, and three were separated. Their ages ranged from 26 to 42, and they had one or two children, the oldest of the children being nine years old and the youngest a three-month-old baby. All men fell into a broad middle class category, although the individual socioeconomic situations varied greatly. 
All interviews but one took place in Mexico City, mostly in the southern area. We met at cafés, bars, their working places, homes, and one interview was carried out via Skype (electronic conferencing). Conversations lasted from two to four hours, during which we would discuss topics that I introduced according to the flow of their stories, although always covering the same topics with each participant. Before starting the interview, I would make clear that the content of our conversations was confidential, and ask them to pick new names for themselves, their children and partners; the choosing of pseudonyms was something that provoked laughs and amusement on many occasions. All the volunteers agreed to have their conversation recorded. While I had been unsure as to whether or not this would have an effect on how they engaged with me, it did not seem to bother them or make them uncomfortable. Before an interview, I would let the men know that I intended to email them a summary of the interview, and that I would ask them later to let me know if they recognised their story in my condensed version of our conversation, indicating the aspects, if any, that were unclear, missing, or wrong. This allowed me to introduce a dialogical aspect not only into the interview but also into the writing phase, allowing these men to have greater control over how they were re-presented by me in the final ethnography. Although elements from the summaries were going to be analysed and discussed in the thesis, I explained, the complete summaries would not be included. They were nonetheless offered their full summary and those of the other participants, together with their copy of the thesis if they so desired. All participants requested their summaries and were pleased with the manner in which their experiences were portrayed, one of them pointing out that although he agreed with the contents of the narrative, reading his own story on paper had been a positive yet bizarre experience.

\section{Women interviewing men}

You have to let these guys know you're on their side. Because in this world of feminism... you know what I mean. (Fellow student)

Just a few days before travelling to Mexico, my classmates and I left the classroom and broke into small groups to discuss our research proposals more thoroughly, especially the aspects having to do with our fieldwork. When talking about each other's position as researchers, a male colleague suggested that if I really wanted men to talk to me, I should let them know I was "on their side". His comment was followed by a heated discussion, which began with the advantages and limitations of doing cross-gender interviews, but quickly detoured into an argument about the meaning of taking sides during research. Listening to my friend's remark made me feel uneasy, puzzled, and frankly a bit upset. In the end I have only to thank him, however, because this comment, and the discussion it generated, triggered a series of reflections having to do with methodological issues, and the very nature of the study I was about to embark on.

The research I was to undertake, even though it was not explicitly placed within a feminist theoretical framework, was indeed very much informed by (Western) feminist perspectives. My study took gender power imbalances and inequalities as a central feature of society at large. Power works in several directions, and the relations and means through which it is exercised are complex, and shaped by a vast range of factors such as age, class and ethnicity. However, historically, women and marginalised masculinities, as it has been increasingly recognised, have experienced the largest share of oppression and subordination in a society that remains stratified by 
gender (Arendell 1997:343, Gutmann 2006). In addition to this, the study of men and masculinity in Latin America maintains a close relationship with feminist scholarship and activism. Gutmann (2003), for instance, conceives masculinity studies in the region as a conscious attempt to extend feminist theory and gender studies in new directions. Much of the impetus and personnel that enabled scholarship on men and masculinities in Latin America, he argues, came from the field of women's and feminist studies in the first place. Although I did not know exactly what my friend was referring to with "this world of feminism", my immediate impression was that he did not think very highly of women holding feminist views. I came to recognise, however, that my colleague did have a point, which related to the question of "how much should a researcher with feminist politics, or any other, for that matter, discuss these with her study's participants" (Arendell 1997:343).

After giving the matter some thought, I decided not to volunteer my position if not asked. First, because I did not want to make participants feel uncomfortable. In the past I had come across several people, men and women alike, who expressed mixed feelings about feminism, even as a broad notion. The other reason for not framing the research in "gender terms" was that I did not want to push men into the politically correct discourse about gender relations and inequality; rather, I wanted them to discuss masculinity, as implicit in their lives, with the kind of terms that they would choose to use themselves. The research was therefore presented as a study that intended to explore men's experiences about being a father in everyday life. I deliberately avoided using terms such as gender, gender roles, inequality, sexism or machismo, so as not to force-fit them into these ready-made categories. Furthermore, I personally find the use of some of those terms to be problematic, such as machismo, which is essentially a stereotype rather than a useful analytic category (see Gutmann 2006 for a discussion on the history and uses of the term machismo). Participants would invariably address gender explicitly, however, every time we discussed paternity leaves, and the possibility of men becoming officially entitled to parental leaves and other benefits, such as state provided daycare, in the near future.

Insights into the role of gender in the qualitative research process and its products, especially insights regarding women studying men, are scarce, although the issue has received more attention in the past years (Arendell 1997, Lee 1997). Besides matters of presentation, such as the one mentioned above, scholars have raised other questions in this regard. Some of these questions include:

what does gender mean for the research process, in general? More specifically, what are the power dynamics when a woman studies men? Do power imbalances shift because of the researcher's expertise with respect to the topic being studied and her initiation in handling the study? Or is the conventional gender hierarchy maintained or re-established across the interaction? Are there variations in these dynamics by race, ethnicity or class, and, if so, how are they shown? (Arendell 1997:343, orig. emph.)

Deborah Lee (1997), for instance, draws on her experiences of discussing harassment at the work place with male participants to reflect upon the implications of addressing sexualised topics in cross-gender interview dynamics. In this article, the author is mainly concerned with the researcher's personal safety and vulnerability, and accompanying questions having to do with control, rapport and reciprocity during interviews. Both Lee and Arendell reported incidents during one-to-one interviews at the participant's home where verbal or physical interaction had made them feel uncomfortable, unsafe and at times harassed. Although this was not the case in my 
study, I do believe that safety and vulnerability issues might often shape the interview dynamics. Early in the fieldwork, I thought of interviewing men who were total strangers to me, and under these circumstances I confess that safety was always at the back of my mind. Originally, interviews were intended to take place at the participants' homes, which was supposed to provide additional data on living conditions and socioeconomic context. However, that idea was soon discarded, since I felt it could place me in a vulnerable position. In the context of the study sample that I eventually found, however, concerns about safety and vulnerability were not a factor when choosing a meeting place. As I mentioned earlier, men in the study were contacted mostly through common friends. In addition to this, all the interviews but one took place in public places. Most of the friends who had introduced us and, as I later found out, partners, children, and close friends of participants were also aware of our encounters.

Beyond personal safety and gender issues, relationships during interviews are complex, and influenced to a certain extent by the identities and histories of those involved, researcher and researched alike (Arendell 1997:364). That being said, while interacting with participants requires a respectful and non-judgmental attitude from the researcher, I do believe a difference exists between establishing an environment of empathy and one of complicity. As it turned out, "choosing sides", by making participants know I was on their side, the issue that my fellow student was most concerned with, never became an issue in this study. Even when stories included difficult or painful experiences, no participant ever made offensive comments about a partner or about women in general. In fact, I was surprised by the extent to which most men in the study were concerned with presenting a balanced picture. In this regard they would not place blame or responsibility solely on one person. An example of this is evidenced in Luis' (34) account, in which, after describing his painful and years-long separation process, he told me: "it is hard for me to talk about these things [the separation] because it implies mentioning very negative things that happened with Jeanne [his partner]. But you know there is never one side to the story and things are always very complex". He proceeded to talk about what he thought it was like to be in his ex-partners' shoes during the separation.

As mentioned above, contrary to Lee and Arendell's experiences, I did not feel vulnerable, disrespected, or even patronised during my interaction with men in the study. Participants would listen to what I had to say and would wait until I finished talking before intervening, in the same way I did with them. Since the purpose of the interviews was to listen to their accounts, they were the ones doing most of the talking, however, none of them tried to take charge or control of the interviews, which was something Arendell encountered when interviewing divorced fathers. Participants took the time they needed to recount their stories, and the time allocated for each of the topics varied greatly from person to person. If responses moved too far from the scope of the research, I would wait for a moment that felt appropriate and try to bring the conversation back by posing another question, or would kindly ask them to go back to their accounts to clarify a particular aspect. None of the volunteers seemed offended or bothered by this, and they would sometimes respond by going back to the point where they had left their story, sometimes by introducing a related issue. Finally, no participant at any time dismissed or ridiculed any of the issues presented for discussion, although a few times they indicated that a question seemed strange, confusing or unnecessary.

Feminist scholars have stressed the need to analyse the role of women as listeners 
during interviews with male volunteers. Arendell found that men in her study had seldom disclosed their experiences and feelings about divorce, and many of them actually thanked her for having the opportunity to share their stories. Something similar happened after many of my own interviews, where men made positive remarks about being able to talk about issues they had not thought of, or talked about in a long time. Or, on the contrary, for having the chance to share aspects of their lives to which they dedicated much thought and reflection, but which they felt nobody else could be interested in or willing to listen to. "People who don't have children are annoyed by these kinds of stories", "this was a nice therapeutic experience", and "I think women talk about this stuff [experiences with children], but you can imagine how it is between men, it is very difficult", were the kind of remarks that would come up often during interviews.

In her own study, Arendell came to the conclusion that it was not so much her as a person with a particular interactional and interview style to whom participants were recounting their stories. In her opinion, they were relating to her on the basis of their expectations of her as a woman, as a feminised Other, which in this context refers to the traditionally feminine role of the passive listener (De Beauvoir 1972, in Arendell 1997). It is by no means the intention here to underplay the fact that differences in gender politics and positions of power can indeed set up interview dynamics in which reproducing gender hierarchies and traditional strategies becomes extremely hard to avoid. However, in my own study, I attribute participants' willingness to talk more to the characteristics of the space generated by our conversations, than to the fact that I was a woman. Our meetings were a mixture of familiarity and anonymity: I was not a total stranger because we had friends in common, but we did not belong to the same group of close friends either. Therefore, in most cases I had never personally met the participants' children, partners or ex-partners, relatives or other friends. The interviews' academic nature probably also helped to render the project more reliable for participants, since several of them worked at the university and were used to discussing and thinking about ethics in research. Most importantly, men in the study were engaged in relationships characterised by partnership rather than subordination, in which major decisions were not imposed but negotiated. In sum, they were men used to listening and taking women's opinions into account, both in their personal and professional lives, and therefore men with whom conversations could be held as equals.

While I feel comfortable asserting that being interviewed by a woman was not a critical factor for sharing their stories, it is possible that participants would have recounted their experiences differently if interviewed by a male researcher. Although the fieldwork experience led me to think that the key characters and events of the stories would have remained basically the same, I wonder if it is possible that participants omitted or emphasised certain elements in their accounts because they were talking to a woman. However, how different participants' narratives would have been is not something I am in a position to determine. In a sense, it is not that important, since stories would also have changed to a certain extent if a female researcher other than me had carried out the interviews. At the end of the day, and this applies to male and female researchers alike, the quality of the interview product relies more on interviewing skills, and a "sense of awareness of the considerable social, historical, and cultural baggage that both researcher and participant bring to their encounters" (Arendell 1997:342). 


\section{Being at home}

Finding a balance between distance and proximity is more than a cognitive problem. Being "at home" refers to the field of emotions as well. (Reis 1998:295)

La Ciudad de México, although not being my place of birth, is the city where I have spent most of my school years, where most of my friends live, and the place I consider to be my home. Neither of my parents are Mexican, however, they settled in Mexico City long ago, even before my brother, who is now 15, was born. Therefore, besides speaking Spanish fluently, among other things, I consider myself a chilanga (an informal way of referring to people who come from Mexico City). Most of the participants in my study had studied or worked at the National University, where I also studied for five years. Seven participants lived in the southern part of the city, and two of them resided in the same neighbourhood where I had lived for ten years. We had similar accents, had acquaintances in common, and belonged to the same middle class group with strong ties to the university life, usually with a background in the humanities, arts or sciences. Going back to Mexico City to do fieldwork did present some immediate advantages. I did not need time to find my way around and did not need to use an interpreter. During interviews participants could speak freely, using slang if needed, making use of cultural references they knew I would share.

However, doing research in one's own city does not necessarily mean being at home, in the sense that it does not guarantee proximity to the participants in the study. The concept of at homeness introduced by Reis (1998), which refers to "shared experiences and processes of identification", was most helpful in this regard, because it allowed me to look at the researcher-researched relationship in a more complex manner, detaching the issue of distance and proximity from the issue of being or not being from a particular geographical location. Widdowfield (1999) stresses the need for acknowledging and analysing the prominent role of emotions in academic research. She argues that despite the increasing recognition that "research is not done by someone 'out there", which has made writing up one's research in the first person a common practice, "the emotions experienced by the researcher and the impact of these in the work undertaken seldom figure in accounts of the research process" (Widdowfield 1999:199-200). This is important, according to Widdowfield, since "not only can emotions affect the research process in terms of what is studied, by whom and in what way, but they may also influence researcher's interpretations, and 'readings' of a situation" (Widdowfield 1999:199-200).

Participants" experiences at times "struck home" because, as a daughter, I could not help but compare some of the accounts with my own story. While listening to the interview recordings, I was amazed and touched by the way men in the study knew their children, and the importance most of them assigned to spending as much time with their children as possible. A few times I caught myself feeling uneasy as well, and having mixed feelings that I could not quite understand. It was only after summarising the last interview that I realized the relationship with my own father had much to do with my motivation for doing this study. Although I was an insider in many ways, I was also an outsider. The first and most obvious reason for this derived from me not being a man or a parent myself. Retrospectively, I have come to realise that my outsider status was also clear in the expectations I had of people (Gilbert 1994:92). Based on my readings and own experience, I was prepared to find a group of men who used a discourse of engaged fatherhood but had a rather disengaged 
practice; however, to my surprise, I found that their practice was fully engaged as well.

\section{The final act}

Anthropological research is a dialogical endeavour, from the formulation of research questions through the writing up of dissertations, books and articles (Fabian 1990, Pool 1994). The type of dialogue I am talking about here includes, although it is not limited to, the verbal interaction that takes place during interviews. Furthermore, invoking dialogue in this context assumes an epistemological position, a way of stressing the "intersubjective nature of ethnographic investigations" (Fabian 1990:765). In the writing-up process, themes from conversations were the basis for discussion and analysis, and some fragments of dialogues were introduced in the body of the dissertation whenever useful for argumentative and explanatory purposes. However, I would like to paraphrase Pool in order to say that the research product was dialogical not only because it contained a series of conversations. Dialogue was considered not "just a question of literary form", but rather "a means to enable us to reflect on the nature of fieldwork and the kind of knowledge which this produces" (Pool 1994:242).

Another assumption that underlaid the research process was the lack of clear boundaries between gathering data and interpretation (Fabian 1990, Pool 1994). This implies that information is not simply collected during fieldwork, but rather produced, constructed. Interviews, which were my main instrument during fieldwork, were not a mere "gathering data exercise" or a "simple transfer of pre-existing information", in the sense that participants did not have "information in their heads ready to be called up in response to my questions" (Pool 1994:26). At the end of the day, as Arendell (1997) has said, in the research process, both participants and researchers bring considerable "baggage" - personal history, identity and understandings - into their interactions, and the way these elements are enacted necessarily affects the interview dynamics, and therefore the accounts and meanings produced.

\section{References}

Arendell, T. 1997. Reflections on the researcher-researched relationship: A woman interviewing men. Qualitative Sociology 20(3), 341-368.

De Beauvoir, S. 1972 [1949]. The second sex. London: Penguin.

De Keijzer, B. 2000. Hasta donde el cuerpo aguante: Genero, cuerpo y salud reproductiva [Until the body can take it: Gender, body and reproductive health]. Mimeo, El Colegio de México, Mexico City.

Escobar-Latapí, A. 2003. Men and their histories: Restructuring, gender inequality, and life transitions in urban Mexico. In Changing men and masculinities in Latin America, ed. M. Gutmann, 84-114. Durham, NC and London: Duke University Press.

Fabian, J. 1990. Presence and representation: The Other in anthropological writing. Critical Inquiry 4(16), 753-772.

Fachel-Leal, O. 2000. Impasses de la paternidad: La reproducción desde la 
perspectiva masculina [Fatherhood: Reproduction from the masculine perspective]. In Paternidades en América Latina [Fatherhoods in Latin America], ed. N. Fuller, 309-331. Lima: Pontificia Universidad Católica del Perú, Fondo Editorial.

Fuller, N. 2001. Masculinidades. Cambios y permanencies [Masculinities, change and permanence]. Lima: Pontifícia Universidad Católica del Perú.

Gilbert, M. 1994. The politics of location: Doing feminist research at "home". Professional Geographer 46(1), 90-96.

Gutmann, M. 1997. The ethnographic (g)ambit: Women and the negotiation of masculinity in Mexico City. American Ethnologist 24(4), 833-855.

--------. 2003. Changing men and masculinities in Latin America. Durham, NC and London: Duke University Press.

-------. 2006. The meanings of macho: Being a man in Mexico City. Berkeley and Los Angeles: University of California Press.

Lee, D. 1997. Interviewing men: Vulnerabilities and dilemmas. Women Studies International Forum 20(4), 553-564.

Olavarría, J. 2003. Men at home? Child rearing and housekeeping among Chilean working-class fathers. In Changing men and masculinities in Latin America, ed. M. Gutmann, 333-350. Durham, NC and London: Duke University Press.

Pool, R. 1994. Dialogue and the interpretation of illness: Conversations in a Cameroon village. Oxford and Providence: Berg.

Reis, R. 1998. Resonating to pain: Introspection as a tool in medical anthropology "at home". Anthropology and Medicine 5(3), 295-310.

Viveros, M. 2002. De quebradores y cumplidores [About promise keepers and promise breakers]. Bogotá: Universidad Nacional - Ford Foundation.

Widdowfield, R. 1999. The place of emotions in academic research. Area 32(2), 199208.

\section{About the author}

Mariana Rios Sandoval currently works for GIRE (Group for Information on Reproductive Choice), a Mexican NGO dedicated to defending and promoting sexual and reproductive rights, particularly abortion rights. Her research interests include gender, feminisms, masculinity studies, critical medical anthropology, sexual and reproductive rights and policies. She can be reached at rios.ma@gmail.com 